\title{
RANCANG BANGUN SISTEM PERINGATAN DINI BANJIR DENGAN MENGGUNAKAN ARDUINO UNO DAN MONITORING LEVEL KETINGGIAN AIR PADA PC DENGAN APLIKASI VISUAL BASIC
}

\author{
Kusmadi $^{1}$, Nur Taupik Sidik ${ }^{2}$ \\ 1,2Program Studi Teknik Elektro, Fakultas Teknik, Universitas Sangga Buana, \\ Bandung, Indonesia. \\ ${ }^{1}$ kusmadi@usbypkp.ac.id
}

\begin{abstract}
ABSTRAK
Tujuan dari Perancangan Prototype Sistem Peringatan Dini banjir ini adalah untuk memberikan peringatan kepada warga jika terjadi banjir, memudahkan pihak pengawas pintu tanggul air untuk mengecek status level ketinggian air melalui Liquid Crystal Display (LCD) dan Personal Computer (PC). Alat ini menggunakan sensor ultrasonik HC-SR04 sebagai sensor utama membaca level ketinggian air sungai. Frekuensi yang yang dipancarkan sensor HC-SR04 yaitu sebesar $40 \mathrm{KHz}$. Sedangkan jarak maksimal yang di deteksi sensor HCSR04 $2 \mathrm{~cm}-400 \mathrm{~cm}$. Data yang diperoleh sensor ultrasonik akan diolah oleh mikrokontroler arduino uno sehingga level ketinggian air dapat tampil pada LCD dan juga PC menggunakan aplikasi visual basic dengan komunikasi Universal Serial Bus (USB). Jika level ketinggian air mencapai batas banjir maka arduino uno akan mengolah data dan selanjutnya akan menyalakan buzzer sebagai peringatan bahwa level ketinggian air akan memungkinkan terjadinya banjir.
\end{abstract}

Kata Kunci: Peringatan dini banjir, Personal computer, Mikrokontroler Arduino Uno, Visual Basic, Sensor Ultrasonik HC-SR04, buzzer.

\section{PENDAHULUAN}

Bencana alam merupakan bencana yang tidak dapat di hindari, tetapi walaupun bencana tersebut tidak dapat dihindari, kita bisa mencegah banyaknya jatuh korban akibat bencana tersebut. Contohnya saat ini yaitu bencana banjir. Pada musim penghujan seringkali beberapa daerah di Indonesia dilanda banjir setiap tahunnya menyebabkan kerugian yang sangat besar bagi warga yang terkena banjir maupun pemerintah. Masalah banjir disebabkan oleh banyak faktor diantarnya seperti saluran air yang meluap dikarenakan tersumbat sampah ataupun menyempitnya sungai-sungai karena bebatuan dan sampah sehingga daya tampung air kurang dan lain sebagainya. Sudah tidak asing lagi di negeri kita disetiap kota besar yang dilalui sungai besar sering terjadi banjir apabila musim hujan datang, yang setiap tahunya memakan korban jiwa ataupun materi.
Tujuan dibuat sistem ini adalah agar dapat memberikan peringatan dini akan adanya bencana banjir, maka diperlukan suatu sistem yang dapat mendeteksi terjadinya perubahan ketinggian air sungai. Untuk itu, perlu dipasang suatu alat yang dapat membaca perubahan tinggi air berupa sensor ultrasonik dilengkapi dengan Mikrokontroller Arduino Uno sebagai alat kontrol sistemnya.

\section{LANDASAN TEORI}

\subsection{Mikrokontroler}

Mikrokontroler adalah suatu IC (Integrated Circuit) dengan kepadatan yang sangat tinggi, dimana semua bagian yang diperlukan untuk suatu kontroler sudah dikemas dalam satu keping ${ }^{[1]}$. Mikrokontroler adalah komputer berukuran mikro dalam satu chip IC (Integrated Circuit) yang terdiri dari processor, memory dan antar muka yang bisa diprogram. Jadi disebut komputer mikro karena dalam IC atau chip mikrokontroler 
terdiri dari CPU, memory dan $\mathrm{I} / \mathrm{O}$ yang bisa kita kontrol dengan memprogramnya. I/O juga sering disebut dengan GPIO (General Purpose Input Output Pins) yang berarti pin yang bisa kita program sebagai input atau output sesuai kebutuhan ${ }^{[2]}$.

\subsection{Arduino Uno}

Arduino adalah sebuah board mikrokontroler yang berbasis ATmega328. Arduino memiliki 14 pin input/output yang mana 6 pin dapat digunakan sebagai output PWM, 6 analog input, crystal osilator 16 $\mathrm{MHz}$, koneksi USB, jack power, kepala ICSP, dan tombol reset. Arduino mampu men-support mikrokontroler, dapat dikoneksikan dengan komputer menggunakan kabel USB.

\subsection{Sensor}

Sensor secara umum didefinisikan sebagai alat yang mampu menangkap fenomena fisika atau kimia kemudian mengubahnya menjadi sinyal listrik baik arus listrik ataupun tegangan ${ }^{[3]}$. Fenomena fisik yang mampu menstimulus sensor untuk menghasilkan sinyal listrik meliputi temperatur, tekanan, gaya, medan magnet cahaya, pergerakan dan sebagainya. Sementara fenomena kimia dapat berupa konsentrasi dari bahan kimia baik cairan maupun gas.

\subsection{Sensor Ultrasonik HC-SR04}

Gelombang ultrasonik merupakan gelombang yang umum digunakan untuk radar untuk mendeteksi keberadaan suatu benda dengan memperkirakan jarak antara sensor dan benda tersebut. Sensor ultrasonik adalah sebuah sensor yang berfungsi untuk mengubah besaran fisis (bunyi) menjadi besaran listrik dan sebaliknya. Cara kerja sensor ini didasarkan pada prinsip dari pantulan suatu gelombang suara sehingga dapat dipakai untuk menafsirkan eksistensi (jarak) suatu benda dengan frekuensi tertentu. Disebut sebagai sensor ultrasonik karena sensor ini menggunakan gelombang ultrasonik (bunyi ultrasonik) ${ }^{[2]}$.

\subsection{Cara Kerja Sensor Ultrasonik}

Pada sensor ultrasonik, gelombang ultrasonik dibangkitkan melalui sebuah alat yang disebut dengan piezoelektrik dengan frekuensi tertentu. Piezoelektrik ini akan menghasilkan gelombang ultrasonik (umumnya berfrekuensi $40 \mathrm{KHz}$ ) ketika sebuah osilator diterapkan pada benda tersebut. Secara umum, alat ini akan menembakkan gelombang ultrasonik menuju suatu area atau suatu target. Setelah gelombang menyentuh permukaan target, maka target akan memantulkan kembali gelombang tersebut. Gelombang pantulan dari target akan ditangkap oleh sensor, kemudian sensor menghitung selisih antara waktu pengiriman gelombang dan waktu gelombang pantul diterima seperti yang dapat dilihat pada gambar 1 .

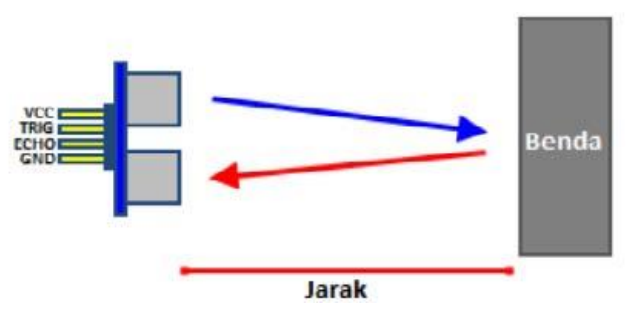

Gambar 1 : Cara Kerja Sensor Ultrasonik

\subsection{LCD (Liquid Crystal Display)}

Display LCD sebuah liquid crystal atau perangkat elektronik yang dapat digunakan untuk menampilkan angka atau teks. Ada dua jenis utama layar LCD yang dapat menampilkan numerik (digunakan dalam jam tangan, kalkulator dll) dan menampilkan teks alfanumerik (sering digunakan pada mesin foto kopi dan telepon genggam $)^{[4]}$.

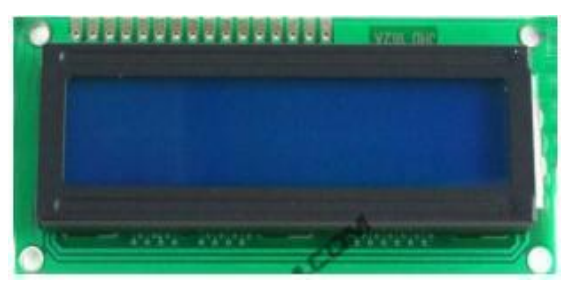

Gambar 2 : LCD 16x2 Character

Klasifikasi LCD 16x2 Character :

1) 16 karakter $x 2$ baris

2) $5 \times 7$ titik Matrix karakter + kursor

3) HD44780 Equivalent LCD kontroler /driver Built-In

4) 4-bit atau 8-bit MPU Interface

5) Tipe standar

6) Bekerja hampir dengan semua mikrokontroler 


\subsection{Buzzer}

Buzzer adalah sebuah komponen elektronika yang berfungsi untuk mengubah getaran listrik menjadi getaran suara. Pada dasarnya prinsip kerja buzzer hampir sama dengan loud speaker, jadi buzzer juga terdiri dari kumparan yang terpasang pada diafragma dan kemudian kumparan tersebut dialiri arus sehingga menjadi elektromagnet, kumparan tadi akan tertarik ke dalam atau keluar, tergantung dari arah arus dan polaritas magnetnya, karena kumparan dipasang pada diafragma maka setiap gerakan kumparan akan menggerakkan diafragma secara bolak $\neg$ balik sehingga membuat udara bergetar yang akan menghasilkan suara ${ }^{[8]}$.
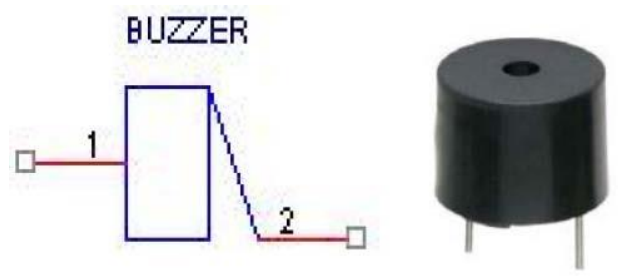

Gambar 3. Buzzer

\subsection{Visual Basic .NET}

Visual Basic .NET adalah bahasa pemograman yang dikembangkan oleh perusahaan Microsoft. Visual Basic .NET merupakan pengembangan dari versi sebelumnya, yaitu Visual Basic 6.0, yang memiliki karakteristik mudah untuk dipahami, namun andal dalam mengikuti tren teknologi perangkat lunak. Perbedaan mendasar antara Visual Basic .NET dengan vesi-versi sebelumnya adalah kemampuan OPP (Object Oriented Programming) yang telah ditanamkan pada Visual Basic .NET. saat ini Visual Basic .NET telah dikolaborasikan dengan beberapa jenis aplikasi, seperti dekstop dan berbasis aplikasi $^{[5]}$.

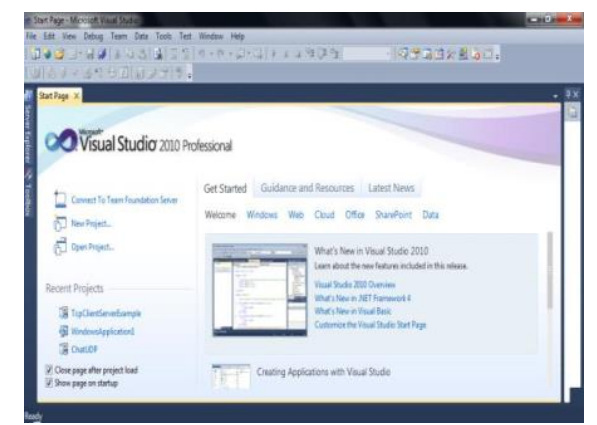

Gambar 4. Tampilan Visual Studio 2010

\subsection{Keunggulan Visual Basic .Net}

Sejak dikembangkannya versi pertama pada tahun 1991 visual Basic kini sampai pada versi terbaru yaitu Visual basic 2010 .

Berikut ini adalah beberapa keunggulan dari Microsoft Visual Basic 2010 .NET :

1. VB.NET mempunyai fasilitas penanganan Bug yang hebat dan Real Time Background Compiler.

2. VB.NET mengatasi semua masalah yang sulit disekitar pengembangan aplikasi berbasis windows.

3. Windows Form designer memungkinkan developer memperoleh aplikasi dekstop dalam waktu singkat.

4. VB.NET menyediakan bagi Developer pemrograman data akses ActiveX Data Object(ADO).

5. VB.NET menghasilkan "Visual Basic untuk Web". Menggunakan form web yang baru, dapat dengan mudah membangun Thin-Client aplikasi berbasiskan web yang secara cerdas dapat berjalan di browser dan Platform manapun. Sebagaimana ditunjukkan pada gambar 6 dibawah ini bahwa WSN terbagi atas 5 bagian, yaitu communication device (transceiver), controller atau mikrokontroler, power suplai, Memory (memori eksternal), dan sensor (actuator).

\section{PERANCANGAN ALAT DAN SISTEM}

Dalam bab perancangan alat dan sistem ini, akan menjelaskan tentang komponen komponen utama dalam perancangan alat dan sistem yang akan berjalan pada alat peringatan dini banjir berbasis arduino uno. Pada dasarnya sistem ini merupakan penyampaian informasi level ketinggian air dengan mikrokontroler sebagai pemrosesan setiap datanya, dimana informasi yang disampaikan didapatkan melalui penerimaan data level tinggi air yang ditampilkan pada LCD dan PC (personal computer) dengan aplikasi visual basic. Data yang masuk akan diolah sehingga pada tampilan LCD maupun personal computer akan menampilkan level ketinggian air serta status peringatan mulai dari aman, siaga dan awas memungkinkan terjadinya banjir. Data tersebut akan 
ditampilkan terus - menerus pada layar LCD dan PC (personal computer) selama alat tersebut terhubung dengan daya listrik.

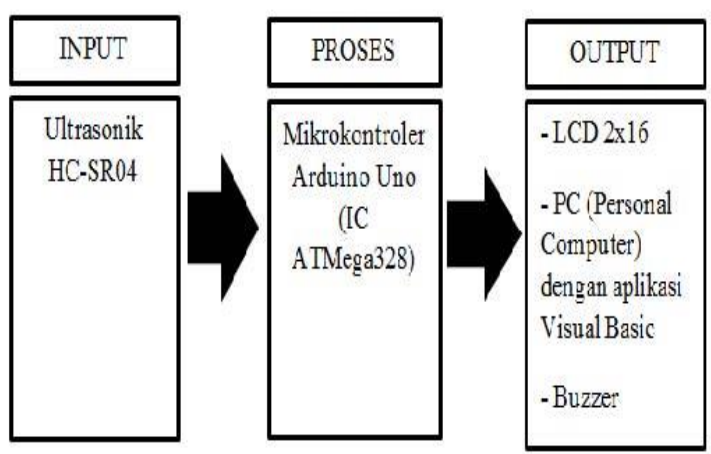

Gambar 5. Blok Diagram Sistem Pedeteksi Dini Banjir

Berdasarkan informasi ini buzzer akan mengeluarkan bunyi sebagai peringatan memungkinkan terjadinya banjir. Pemantauan dan layanan peringatan dini dapat meningkatkan kemampuan untuk menghadapi ancaman banjir dan dapat menjadi solusi untuk petugas pintu tanggul air dan masyarakat agar dapat melakukan evakuasi sebelum banjir datang.

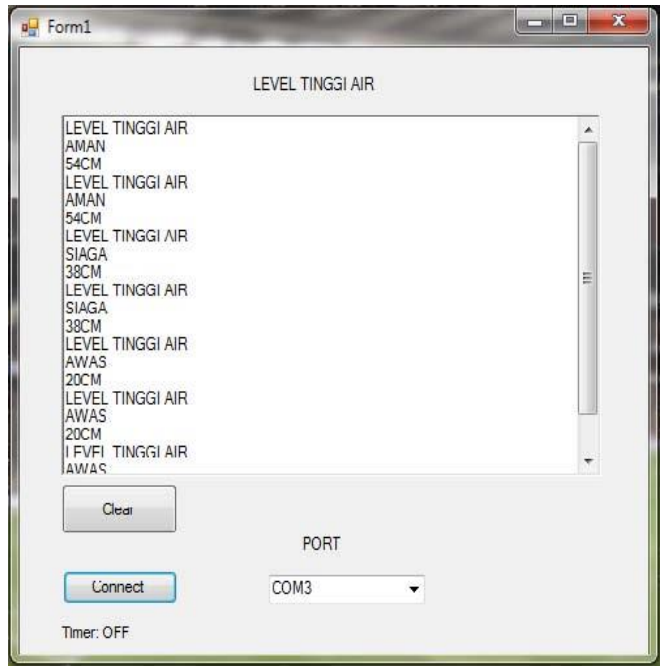

Gambar 6. Tampilan Visual Basic

\subsection{Cara Kerja Sistem}

Cara kerja dari sistem peringatan dini banjir ini adalah sensor ultrasonik digunakan sebagai sensor utama dalam membaca level ketinggian air, dengan jarak yang dapat dibaca oleh sensor mencapai $8 \mathrm{~cm}-400 \mathrm{~cm}$ yang nantinya jarak level air tersebut akan ditampilkan secara langsung melalui LCD (liquid crystal display) dan visual basic beserta status apakah level ketinggian air tersebut berada di level aman, siaga atau awas sesuai program ketentuan jarak yang telah kita upload pada arduino uno.

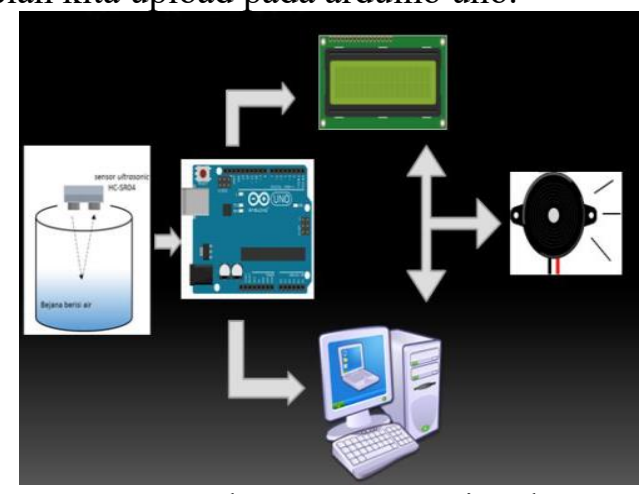

Gambar 7. Cara Kerja Alat

Pada saat level ketinggian air mencapai level siaga dan awas disini sebuah buzzer akan berbunyi dengan suara yang berbeda sesuai program yang telah kita atur didalamnya, yang akan berbunyi pada level siaga dan awas.

\section{PENGUJIAN DAN ANALISA}

Bab ini berisi penjelasan tentang metode dan prosedur pengujian yang dilakukan serta hasil yang diperoleh dari masing-masing blok sistem tersebut. Pengujian dan pembahasan dilakukan untuk mengetahui kesesuaian antara perancangan awal sistem terhadap alat yang dihasilkan, dapat bekerja dengan baik atau tidak. Pengujian yang dilakukan secara bertahap per blok-blok sistem dari keseluruhannya. Pengujian dimulai dengan memastikan setiap komponen yang digunakan dalam kondisi bagus (dapat bekerja dengan baik), kemudian mengecek setiap jalur yang terhubung dengan komponen yang digunakan diatas papan PCB telah terkoneksi, dimana rangkaiannya disesuaikan dengan gambar skematiknya.

Pengujian yang dilakukan meliputi pengujian sensor ultrasonik HC-SR04 sebagai rangkaian pemancar dan penerima ultrasonik, board arduino uno, penampil LCD (liquid crystal display), komunikasi data port serial antara board arduino dengan PC (personal computer) dengan aplikasi visual basic dan pengujian sistem secara keseluruhan.

\subsection{Pengujian Input}

Sensor ultrasonik HC-SR04 diuji dengan bantuan mikrokontroler arduino uno untuk memicunya, sensor ultrasonik akan membaca 
jarak benda yang terkena pantulan gelombang untrasoniknya. Gambar rangkaian dapat dilihat pada gambar 8, dan pada mikrokonroler arduino uno diinputkan listing (ultrasonik demo).

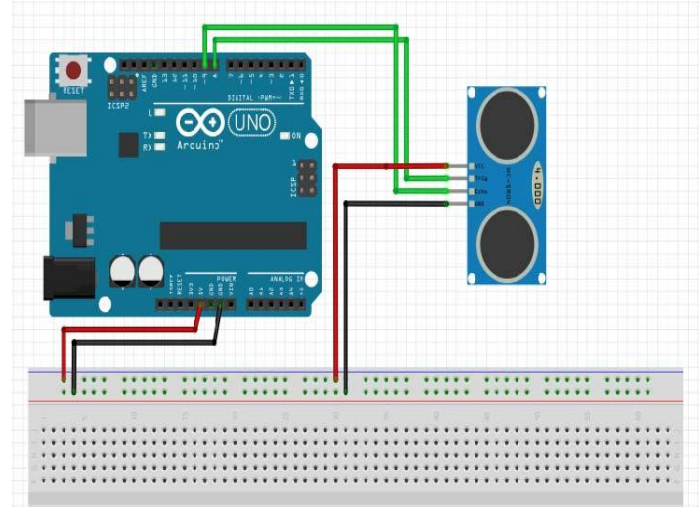

Gambar 8. Rangkaian Uji Sensor Ultrasonik HC-SR0

Pengujian dilakukan dengan cara menggerakan sebuah benda mendekati dan menjauhi sensor ultrasonik, dan diperoleh sebuah jarak benda yang ditampilkan pada serial monitor yang terdapat pada menu pemograman Arduino IDE. Hal ini menunjukan bahwa sensor ultrasonik HCSR04 berfungsi dengan baik, karena perubahan jarak yang dilakukan terhadap sensor direspon dengan perubahan jarak yang tampil pada serial monitor. Berikut adalah tampilan jarak yang terbaca oleh sensor ultrasonik HC-SR04 yang ditampilkan oleh serial monitor.

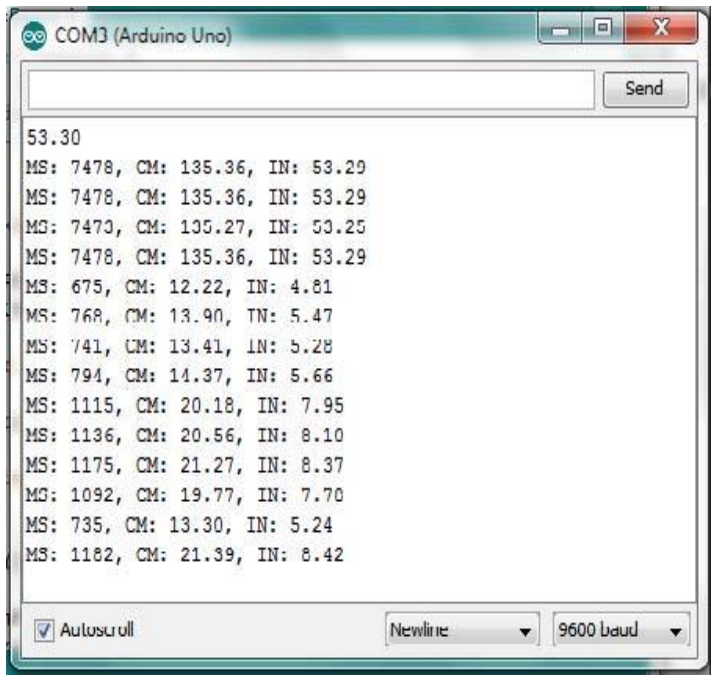

Gambar 9. Menu Serial Monitor Penampil Data Jarak Sensor

\subsection{Pengujian Proses Arduino Uno}

Pengujian arduino uno dilakukan untuk mengetahui apakah program dapat di-upload dan dijalankan oleh arduino uno sebagai proses untuk menjalankan semua sistem yang nantinya akan dihubungkan pada ardino uno.

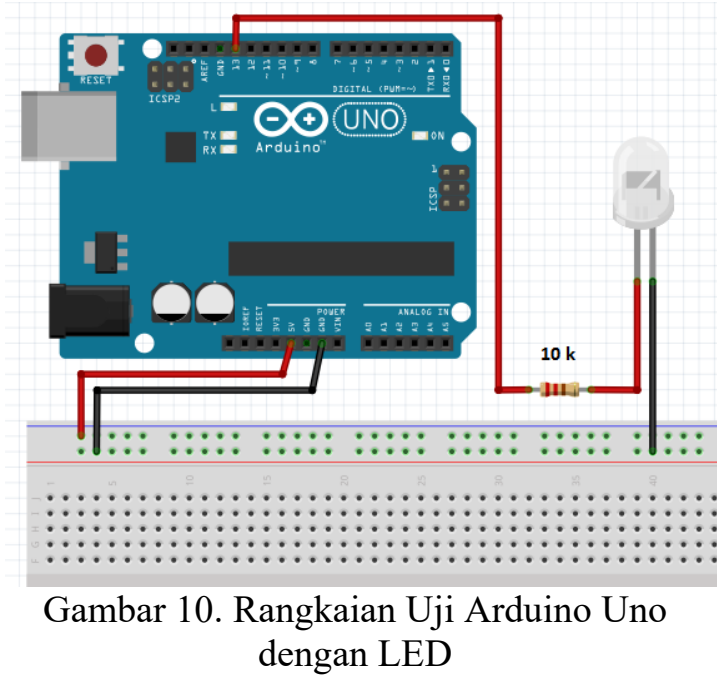

Program yang akan digunakan untuk pengujian arduino uno adalah program Blink yaitu program untuk menghidupkan dan mematikan lampu LED secara bergantian terus-menerus selama satu detik, yang dihubungkan pada pin 13 board arduino uno. Gambar rangkaiannya dapa dilihat pada gambar 10, dan pada mikrokontroler arduino uno diinputkan listing program Blink.

\subsection{Pengujian Output \\ 4.3.1. Pengujian LCD 16x2}

Rangkaian penampil LCD (liquid crystal display) diuji dengan bantuan mikrokontrol arduino uno, rangkain seperti pada gambar 4.8. dalam rangkaian ini LCD yang digunakan adalah tipe RG1602A yang merupakan piranti display yang mampu menampilkan karakter 16 kolom dan 2 baris (16 x 2), yang dihubungkan pada mikrokontrol arduino uno.

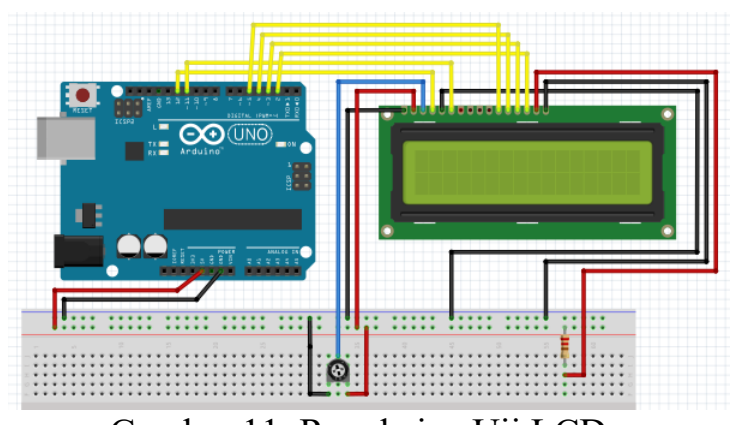

Gambar 11. Rangkaian Uji LCD 


\subsubsection{Pengujian Buzzer}

Buzzer diuji dengan bantuan mikrokontrol arduino uno untuk memicunya, yaitu dengan membunyikan buzzer hidup dan mati selama satu detik secara bergantian terus-menerus dan ditambah dengan sebuah lampu LED sebagai tanda bahwa mikrontrol arduino uno memberikan sinyal high atau low. Buzzer dan lampu LED dihubungkan pada pin 13 arduino uno gambar rangkainnya dapat dilihat pada gambar 12 dengan listing program Blink.

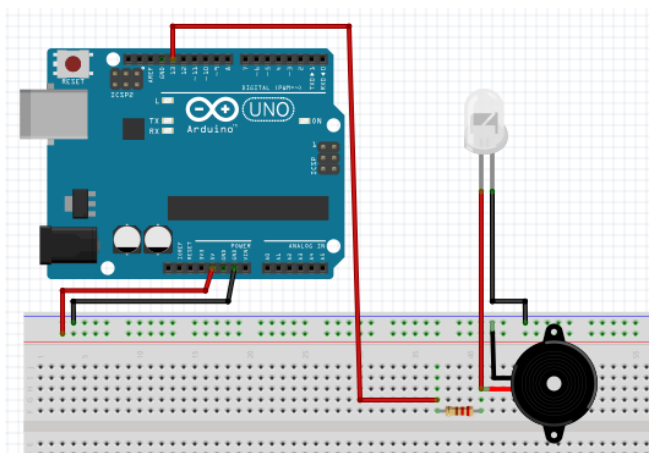

Gambar 12. Rangkaian Uji Buzzer dengan LED

\subsection{Pengujian Visual Basic}

Tampilan visual basic diuji dengan bantuan arduino uno dan sesnsor ultrasonik, yaitu dengan cara menghubungkan board arduino uno dengan PC (personal computer) melalui komunikasi USB. Menu yang terdapat pada form visual basic akan difungsikan dengan cara dihubungkan dengan board arduino uno untuk melihat apakah form visual basic dapat terhubung dan menampilkan data dari arduino uno.

\section{\begin{tabular}{|c|c|c|} 
PORT \\
\hline Dis-connect \\
Gambar 13. Port Visual Basic Sudah \\
Terhubung Dengan Arduino Uno
\end{tabular}}

\subsection{Pengujian Sistem Keseluruhan}

Pengujian sistem secara keseluruhan yaitu melakukan pengujian terhadap seluruh sistem dari perancangan yang telah dibuat, pengujian keseluruhan ini dilakukan setelah pengujian terhadap masing-masing blok sistem selesai diuji.

Dalam pengujian ini sistem perancangan terdiri dari dua modul. Pertama modul yang berada pada sisi mikrokontroleh arduino uno, berfungsi sebagai pemancar dan penerima gelombang ultrasonik, penghitung jarak ketinggian air, menampilkan pada LCD dan mengirimkan hasil tersebut pada PC/laptop melalui komunikasi USB. Sedangkan modul ke dua yaitu sisi PC/laptop sebagai penampil hasil pemantauan level ketinggian air secara real time dilapangan dalam aplikasi visual basic. Berikut ini adalah blok diagram dari sistem keseluruhan.

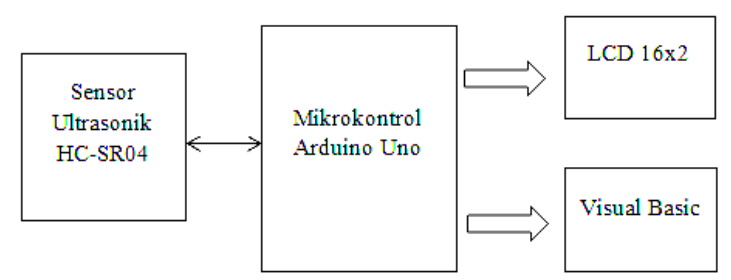

Gambar 14. Diagram Blok Sistem Keseluruhan

\subsubsection{Hasil Uji Coba Keseluruhan}

Pada rangkaian dan aplikasi software yang dibuat penulis perlu melakukan uji coba untuk memastikan apakah rangkaian dan aplikasi software ini dapat berjalan dengan baik dan tidak terjadi masalah pada saat digunakan. Untuk pengujian sistem secara keseluruhan ini dilakukan pada sebuah wadah yang diisi air yang permukaan airnya secara perlahan mendekati sensor ultrasonik.

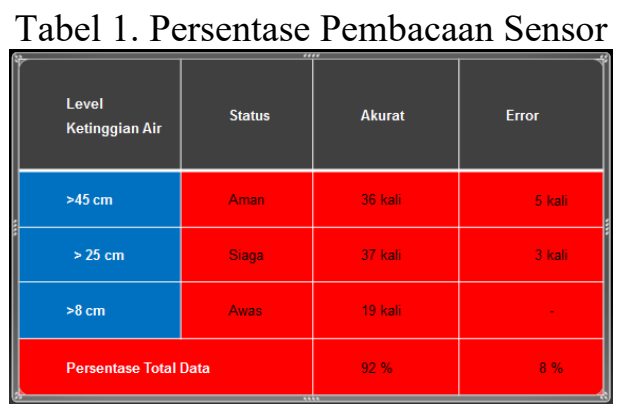

\subsubsection{Analisa Hasil}

Dari tabel 1 tersebut dapat kita lihat bahwa terjadinya kesalahan pembacaan sensor yaitu pada level ketinggian air lebih dari $45 \mathrm{~cm}$ dan lebih dari $25 \mathrm{~cm}$ yang berada pada status Aman dan Siaga terjadi 8 kali kesalahan dari 100 kali pembacaan sensor. Hal ini disebabkan karena permukaan air yang tidak beraturan atau bergelombang pada saat pengisian air di wadah, sehingga sensor ultrasonik tidak dapat membaca dengan akurat jadi data yang seharusnya diterima berurutan karena level air perlahan naik 
menjadi tidak berurutan atau level air terlihat naik turun.

\section{KESIMPULAN DAN SARAN}

\subsection{Kesimpulan}

Berdasarkan hasil analisis dan pengujian terhadap sistem peringatan dini banjir ini maka dapat disimpulkan bahwa :

1. Prototype Sistem Peringatan Dini Banjir dengan Menggunakan Arduino Uno dan Monitoring Level Ketinggian Air pada PC dengan Aplikasi Visual Basic berhasil diimplementasikan.

2. Sistem peringatan dini banjir ini berjalan dengan baik untuk nilai pengukuran $8 \mathrm{~cm}$ - $61 \mathrm{~cm}$ dengan 100 kali pembacaan sensor dari tingkat persentase kesalahan hanya $8 \%$.

3. Kecepatan sensor membaca level ketinggian air langsung ditampilkan pada LCD dan Visual Basic pada PC adalah 1 detik. Sehingga data yang diperoleh dapat langsung terlihat secara real time.

4. Pada buzzer tidak terjadi error dan berfungsi ketika level air berada pada status Siaga dan Awas.

\subsection{Saran Pengembangan}

Untuk pengembangan labih lanjut atas prototipe yang berhasil diimplementasikan, diantaranya:

1. Sensor ultrasonik yang digunakan lebih baik tahan terhadap air agar dapat terus digunakan dan tidak terjadi kerusakan ketikan sensor terendam air. Dapat diganti dengan sensor ultrasonik waterproof yaitu sensor ultrasonik tipe JSN-SR04T, MB7066 XL-MaxSonarWRL1 dll.

2. Aplikasi visual basic yang digunakan selain untuk menampilkan level ketinggian air dan status sebaiknya dapat menyimpan database level ketinggian air, sehingga data tersebut dapat dijadikan kumpulan informasi yang dapat diperiksa untuk keperluan penelitian mengenai banjir disuatu daerah.

3. Untuk tampilannya bisa diganti dengan seven segment atau media tampilan yang lebih besar sehingga dapat memudahkan untuk melihat level ketinggian air bagi masyarakat maupun pengawas pintu air.

\section{DAFTAR PUSTAKA}

[1] Putra, Agfianto Eko dan Nugraha, Dhani, 2011, Tutorial Pemograman Mikrokontroler AVR dengan AVR Studio dan WinAVR GCC (ATMega16/32/8535), Yogyakarta : Universitas Gajah Mada.

[2] Hari Santoso, 2015, Ebook Panduan Praktis Arduino Untuk Pemula, www.elangsakti.com

[3] http://www.scribd.com/doc/18271343/6/Pe ngertian-Umum-Sensor (diakses pada tanggal 4 juni 2016)

[4] Syahrul, 2014, Pemograman Mikrokontroler AVR Bahasa Asembly dan C, informatika, Bandung

[5] Alexander F.K. Sibero, 2010, Dasar - dasar Visual Basic .NET, MedikaKom, Yogyakarta

[6] http://terminaltechno.blog.uns.ac.id/2009/1 1/07/pengkabelan-port-serial-port-paralelusb-dan-port-serial-rs-232/ (diakses pada tanggal 21 agustus 2016)

[7] http://www.usb.org/developers/docs/docu ments archive/ (diakses pada tanggal 21 agustus 2016)

[8] http://www.cui.com/product/resource/buzz ers buzzersounds .pdf, (diakses pada tanggal 4 juni 2016)

[9] Phil,Jones (2001). Visual Basic A Complete Course Letts Higher Education List Series. Cengange Learning EMEA. Liberty, Jesse (2005). Programming Visual Basic 2005 O’Reilly Series Safari Books Online. O'ReillyMedia Inc. 